\title{
Chemoradiotherapy for Local Recurrence of Rectal Cancer: A Single Center Study of 18 Patients
}

\author{
JUNKO WATANABE ${ }^{1}$, HIROKAZU SHOJI $^{1}$, TETSUYA HAMAGUCHI ${ }^{1,2}$, TAKAHIRO MIYAMOTO ${ }^{1}$, \\ HIDEKAZU HIRANO ${ }^{1}$, SATORU IWASA ${ }^{1}$, YOSHITAKA HONMA ${ }^{1}$, ATSUO TAKASHIMA ${ }^{1}$, \\ KEN KATO $^{1}$, YOSHINORI ITO ${ }^{3,4}$, JUN ITAMI $^{3}$, YUKIHIDE KANEMITSU ${ }^{5}$ and NARIKAZU BOKU ${ }^{1}$ \\ ${ }^{1}$ Gastrointestinal Medical Oncology Division, National Cancer Center Hospital, Tokyo, Japan; \\ ${ }^{2}$ Saitama Medical University, International Medical Center, Saitama, Japan; \\ ${ }^{3}$ Department of Radiation Oncology, National Cancer Center Hospital, Tokyo, Japan; \\ ${ }^{4}$ Department of Radiation Oncology, Showa University School of Medicine, Tokyo, Japan; \\ ${ }^{5}$ Colorectal Surgery Division, National Cancer Center Hospital, Tokyo, Japan
}

\begin{abstract}
Background/Aim: When possible, surgical resection is recommended for local recurrence after resection of colorectal cancer. In unresectable cases, chemotherapy is usually indicated, although the success of chemoradiotherapy $(C R T)$ in this setting is unclear. Patients and Methods: We retrospectively reviewed the treatment outcomes of 18 patients who received CRT for unresectable local recurrence after radical colorectal cancer surgery at our hospital between January 2000 and May 2016. Results: Of these 18 patients, three experienced complete response and four experienced partial response, resulting in a $39 \%$ overall response. With a median follow-up time of 42 months, the 5-year progressionfree survival and overall survival were $34.8 \%$ and $54.4 \%$, respectively; associated with a median local failure-free survival time of 40.9 months. Two of the three patients that underwent CRT remained local failure free for 5 years. Conclusion: CRT for local recurrence of rectal cancer without distant metastasis produces similar overall survival rates and local control as conventional surgical resection.
\end{abstract}

Despite significant advances in the multidisciplinary management of primary rectal cancer, local recurrence still develops. Local recurrence rates after surgery alone in patients with rectal cancer range between 5-10\% (1). In addition, preoperative chemoradiotherapy (CRT) has been

This article is freely accessible online.

Correspondence to: Hirokazu Shoji, MD, PhD, Gastrointestinal Medical Oncology Division, National Cancer Center Hospital, Tsukiji 5-1-1, Chuo-ku, Tokyo 104-0045, Japan. Tel: +81 335422511, e-mail: hshouji@ncc.go.jp

Key Words: Rectal cancer, local recurrence, chemoradiotherapy. associated with a pathological complete response in $15-20 \%$ of treated patients (2-5). The recommended therapeutic strategy for local recurrence of rectal cancer is surgical resection, if microscopically complete (R0) resection is possible. The 5-year survival rate after surgery in patients with local recurrence is $20-40 \%$ (6-8). However, the decision to perform curative surgery is made difficult by several factors: recurrence pattern, involvement of adjacent organs, medical unfitness, or patients' refusal due to the considerable risk of morbidity and mortality.

Radiotherapy (RT) for local recurrence of rectal cancer is a demonstrated effective treatment; it can also control symptoms such as pain. Recently, the ability of CRT using various anticancer drugs to improve treatment outcomes has been investigated. In a randomized controlled study of unresectable $\mathrm{T} 4$ rectal cancer or local recurrence of rectal cancer, 5-fluorouracil (5-FU)/leucovorin administered concurrently with radiation therapy was superior to RT alone with regard to local control, cancer-specific survival, and overall survival (9). This was despite the apparently higher toxicity associated with CRT. For local recurrence of rectal cancer, it is therefore considered that CRT may provide better outcomes compared with RT alone, if patients have not been previously irradiated. However, there have been few previous reports on the outcome of CRT.

The objective of this retrospective study was to clarify the treatment outcomes of CRT in patients with local recurrence of rectal cancer, and explore any difference in outcomes according to the combined chemotherapy regimens.

\section{Patients and Methods}

Patients. The subjects of this study were patients with local recurrence of rectal cancer treated with CRT between January 2000 and May 2016 with a curative intent at the National Cancer Center Hospital. The following data of the patients were collected by 
reviewing the medical chart: age, sex, Eastern Cooperative Oncology Group performance status (ECOG PS), interval between surgery and recurrence, size of the recurrent lesions, adjuvant chemotherapy, and reasons for selecting CRT. Imaging examinations were repeated every 8 weeks after the initiation of treatment. In patients with measurable target lesions, the objective response rate (ORR) was assessed according to the response evaluation criteria in solid tumors (RECIST) version 1.1. Toxicity was evaluated according to the National Cancer Institute Common Toxicity Criteria for Adverse Events, version 4.0 (NCI CTCAEv4.0). This study was reviewed and approved by the institutional ethics committee of the National Cancer Center.

Chemoradiotherapy regimens. All patients received external beam radiation (50 to $60 \mathrm{~Gy}$ ) with concurrent chemotherapy such as 5-FU continuous infusion (ci), or S-1, weekly 5-FU ci plus oxaliplatin, modified FOLFOX6 (mFOLFOX). 5-FU ci regimen was a continuous infusion of $2500 \mathrm{mg} /$ week $\mathrm{mg} / \mathrm{m}^{2}$ of $5-\mathrm{FU}$ (7 days), repeated every week. S-1 was administered orally at the dose of $80 \mathrm{mg} / \mathrm{m}^{2} /$ day. Weekly 5 -FU ci plus oxaliplatin regimen consisted of intravenous infusion of $50 \mathrm{mg} / \mathrm{m}^{2}$ of oxaliplatin $(2 \mathrm{~h})$ on day 1 and continuous infusion of 2,500 mg/week 5-FU (7 days), repeated every week. The mFOLFOX regimen consisted of intravenous infusion of $85 \mathrm{mg} / \mathrm{m}^{2}$ of oxaliplatin $(2 \mathrm{~h}), 200 \mathrm{mg} / \mathrm{m}^{2}$ 1-leucovorin ( 2 hours), and $400 \mathrm{mg} / \mathrm{m}^{2}$ bolus 5 -FU on day 1 , followed by a continuous infusion of $2,400 \mathrm{mg} / \mathrm{m}^{2}$ of 5 -FU $(46 \mathrm{~h})$, repeated every 2 weeks. Chemotherapy started from the first day and was repeated to the last day of radiotherapy in all patients, and subsequent chemotherapy regimens were determined by each physician's discretion according to the efficacy and toxicities of CRT. Six patients continued to receive chemotherapy until disease progression after the completion of radiation therapy.

Statistical analysis. Overall survival (OS) was defined as the time from the initiation of CRT to death from any cause or censored at the last follow-up. Progression-free survival (PFS) was defined as the time from the initiation of CRT to disease progression or death from any cause. Patients without disease progression who were lost to follow-up were censored at the last observation. Local failurefree survival (LFS) was defined as the time from the initiation of CRT to local disease progression or death regardless of distant metastasis, and all other events were censored at the last follow-up. PFS, OS, and LFS were estimated using the Kaplan-Meier method, and compared using the log-rank test. All the statistical analyses were performed using the JMP version 3.0 software.

\section{Results}

Patient characteristics. Eighteen patients, who underwent CRT with a curative intent for local recurrence after radical resection of rectal cancer between January in 2000 and May in 2016 at this hospital, were identified as the subjects of this study. None of them had previously been treated with radiotherapy to the pelvis.

Patient characteristics are shown in Table I. The median age of the patients was 66 years (range $=27-80$ years) and the ECOG PS was PS 0 in six patients, PS 1 in 11 patients, and PS 2 in one. None of the patients had metastatic lesions, and all had only local recurrence. Ten had a history of
Table I. Patient characteristics.

\begin{tabular}{lcc}
\hline & $\mathrm{N}=18$ & $\%$ \\
\hline Age, median (range) & 66 & $(27-80)$ \\
Gender & 13 & 72.2 \\
$\quad$ Male & 5 & 27.8 \\
$\quad$ Female & & \\
Performance status & 6 & 33.3 \\
0 & 11 & 61.1 \\
1 & 1 & 5.6 \\
2 & & \\
Histology & 18 & 100 \\
$\quad$ Adenocarcinoma & 10 & 55.6 \\
Adjuvant chemotherapy & 8 & 44.4 \\
$\quad$ Yes & & \\
$\quad$ No & 17.5 months & $(4-56)$ \\
The median period of time between & 49 mm & $(15-100)$ \\
surgery and local recurrence (range) & & \\
Tumor size, median (range) & 11 & 61.1 \\
Reasons for selecting CRT & 4 & 22.2 \\
Unresectable disease & 2 & 11.1 \\
Advanced age & 1 & 5.6 \\
Complication &
\end{tabular}

fluoropyrimidine-based adjuvant chemotherapy. The median period of time between surgery and local recurrence was 17.5 months (range=4-56 months). The reasons for selecting CRT as the salvage treatment for local recurrence were unresectable disease in 11 patients, advanced age in four, complications in two, and refusal of surgery in one.

Doses of radiation were 59.4 Gy in 16 patients, 50 Gy in one, and $60 \mathrm{~Gy}$ in one, considering the radiation field and concurrent chemotherapy regimens. Fourteen patients $(78 \%)$ received $3 \mathrm{D}$ conformal radiation therapy, and four patients $(22 \%)$ received intensity modulated radiation therapy. Concurrent chemotherapy regimens were 5-FU ci plus weekly oxaliplatin in ten patients $(56 \%)$, modified FOLFOX6 in four (22\%), 5-FU ci in two (11\%), and S-1 in two $(11 \%)$. All patients had measurable lesions.

Treatment outcome. Of these 18 patients, three patients achieved complete response (CR), resulting in a CR rate of $17 \%$, and four patients experienced partial response (PR), indicating that the response rate was $39 \%$ (7/18). Ten patients experienced stable response (SD), and the disease control rate was $94 \%(17 / 18)$. With a median follow-up period of 42 months (range=5-81 months), the 5-year PFS rate was $34.8 \%(95 \% \mathrm{CI}=13.6-64.5$; Figure 1). Five patients were still alive without disease progression in July 2017. In the remaining patients, disease progression patterns were local failure in five patients, both local failure and distant metastasis in four patients (three lung metastasis and one 


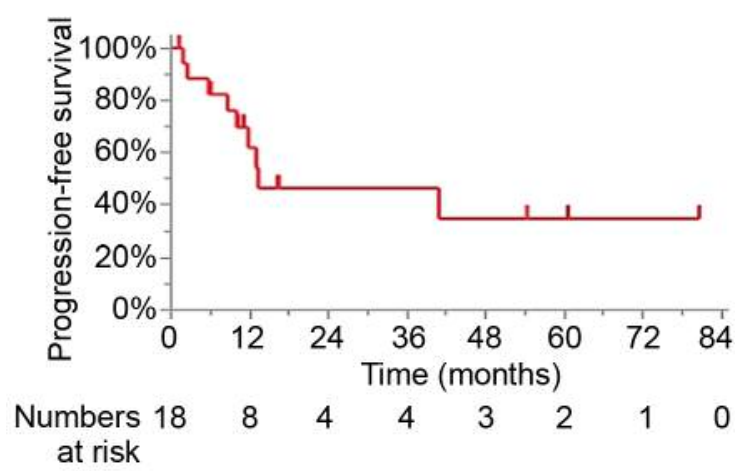

Figure 1. Progression-free survival curve calculated using the KaplanMeier method.

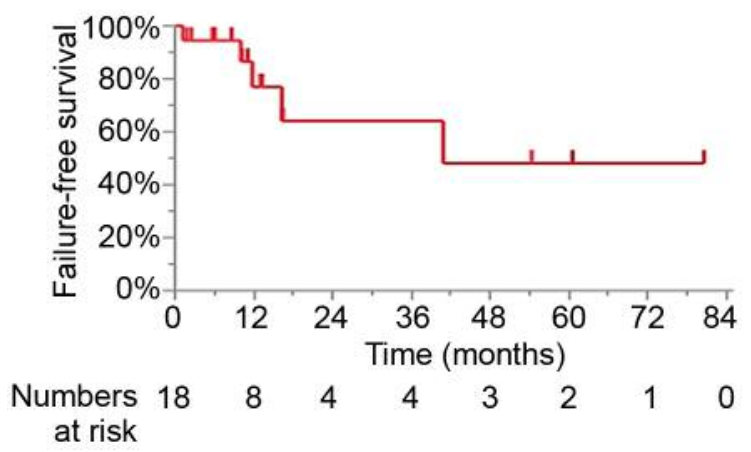

Figure 2. Local failure-free survival curve calculated using the KaplanMeier method.

mediastinal lymph node metastasis). The median LFS duration was 40.9 months (Figure 2). Of the three patients who achieved CR, two showed an LFS longer than 5 years. The 5-year OS rate was 54.4\% (95\% CI=27.3-79.2; Figure 3). There was no significant difference in 5 -year OS between CRT using doublet chemotherapy and 5-FU-based monotherapy $(51.1 \%$ vs. $50.0 \%$ for doublet regimen and monotherapy groups, respectively; $p=0.50$ ) (Figure 4).

Adverse events. Grade 3 or higher hematological toxicities were observed in three patients (17\%): white blood cell count decreased in one patient and neutrophil count decreased in two. Grade 3 or higher non-hematological toxicities were observed in five patients $(28 \%)$ : diarrhea in three patients, stomatitis in one, and allergy in one. No severe late toxicity was observed during follow-up.

Three cases achieving CR. Case 1: A 53-year-old female had undergone transanal local resection for rectal cancer (cT1N0M0). She received adjuvant chemotherapy with

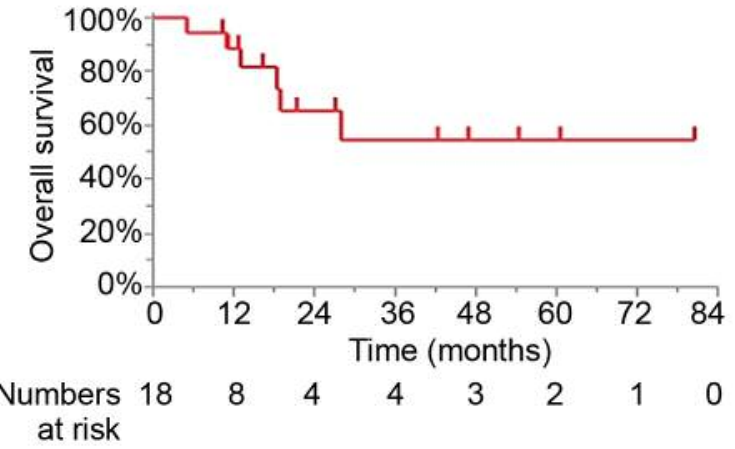

Figure 3. Overall survival curve calculated using the Kaplan-Meier method.

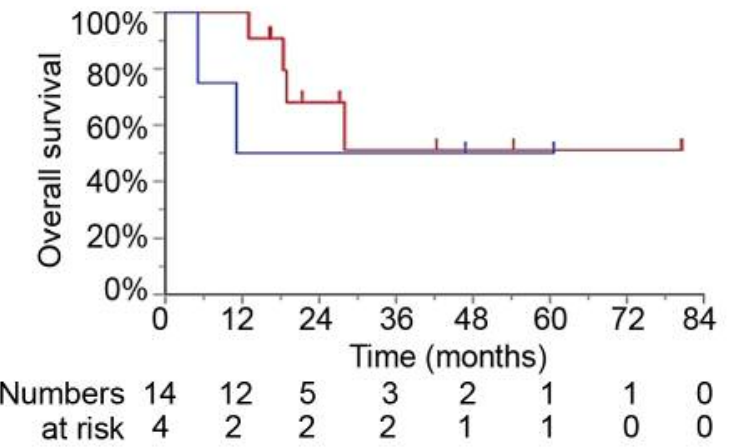

Figure 4. Overall survival curves using the Kaplan-Meier method for groups classified according to the treatment regimens.

tegafur/uracil (UFT) and oral leucovorin for 6 months. Four years after surgery, pelvic CT scans revealed a $5-\mathrm{cm}$ mass anterior to the sacrum. Weekly 5-FU ci plus oxaliplatin were delivered concurrently with RT (total dose $59.4 \mathrm{~Gy}$ ) which was given to the pelvic lesion. 18F-fluorodeoxyglucose (FDG) Positron Emission Tomography (PET) showed no uptake after CRT, and LFS was 81 months (Figure 5a).

Case 2: A 50-year-old male had undergone a low anterior resection (D2) for lower rectal cancer (cT1N0M0). He did not receive adjuvant chemotherapy. Nine months after surgery, colonoscopy revealed a $3-\mathrm{cm}$ mass in the anastomosis. S-1 was delivered concurrently with RT (total dose 59.4 Gy). He experienced CR. However, thirteen months after CRT (Figure 5b), he was diagnosed with mediastinal lymph node metastases.

Case 3: A 75-year-old male had undergone a low anterior resection (D2) for lower rectal cancer (cT1NOM0). He took capecitabine for 6 months as adjuvant chemotherapy. Eighteen months after surgery, CT revealed a $2-\mathrm{cm}$ mass in the lateral site of the pelvis. S-1 was delivered concurrently 


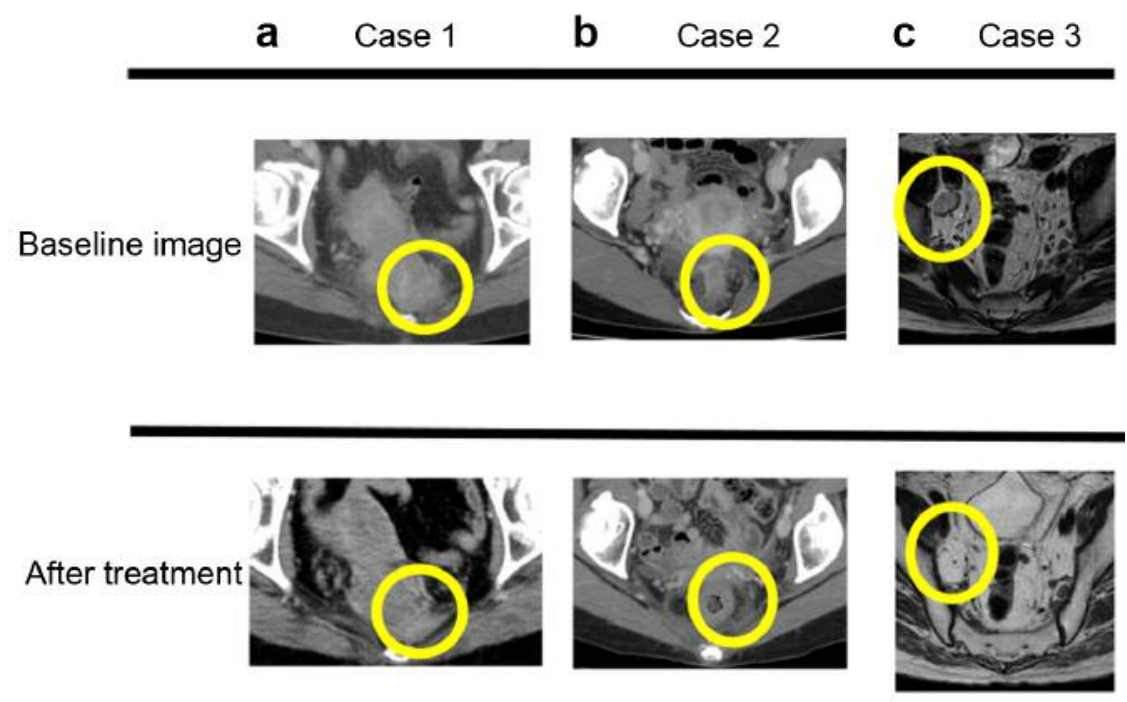

Figure 5. CT or MRI scan images of patients who achieved complete response.

with RT (total dose 59.4 Gy). He experienced CR and obtained LFS for 5 years (Figure $5 \mathrm{c}$ ).

\section{Discussion}

There is no consensus regarding the treatment modality for local recurrence of rectal cancer. Although radical resection remains the first choice with a potential for cure, only approximately $20-40 \%$ of patients with recurrent rectal cancer are eligible for R0 resection (10-12). For patients who are not eligible, Bhangu et al. reported that there was no significant difference in long-term survival between R2 resection and those treated with non-surgical modalities (13). Thus, if curative resection (R0) cannot be performed, surgical resection is not expected to have a superior benefit. At this stage in the treatment of patients, radiation therapy and systemic chemotherapy alone or in combination should be taken into consideration $(14,15)$. In this retrospective study, we investigated the efficacy of CRT for the treatment of local recurrence of rectal cancer without distant metastasis. In our clinical experience, the response rate was $39 \%(7 / 18)$, and disease control rate was 94\% (17/18); no severe adverse events were observed. Furthermore, CR was observed in 3 of 18 patients $(16.7 \%)$, two of whom had LFS of more than 5 years.

The addition of 5-FU is reported to promote longer survival than RT alone for locally unresectable rectal cancer $(16,17)$. Furthermore, Ito et al. reported that CRT (continuous infusion of 5-FU+RT) was more effective than RT alone in 30 patients with local recurrent rectal cancer (18). The treatment outcomes resulted in a response rate of $31 \%$, a disease control rate of $100 \%$, and a median OS period of 15.1 months, with manageable toxicities. Their report also showed an increase in the median OS of patients treated with CRT compared with RT alone (median survival time 9.3 months). Furthermore, CRT was effective for pain relief, and 5-FU based regimens were confirmed to be effective and safe. In comparison with their report on CRT, our result showed comparable survival effects of CRT. Median OS in our study was not reached, and the survival in our study was more favorable than the CRT group in Ito's study. This difference in efficacy between the Ito study and our current report may be due to the differences in the chemotherapeutic regimens and radiation therapy. Specifically, 5-FU alone and a median total dose of $50 \mathrm{~Gy}$ were evaluated by Ito et al. whereas several types of chemotherapy regimens, including oxaliplatin and a median total dose of $60 \mathrm{~Gy}$, were examined in our study.

Since oxaliplatin was introduced into clinical practice, substantial progress has been made in chemotherapy of colorectal cancer. Chemotherapy with oxaliplatin combined with 5-FU, such as the FOLFOX regimen, is more effective and has become the standard treatment for advanced stage colorectal cancer $(19,20)$. Furthermore, preoperative CRT using an oxaliplatin-containing regimen for locally advanced rectal cancer showed a high success rate with toxicity within tolerable limits $(21,22)$. Among previous studies on CRT that incorporated oxaliplatin-containing regimen for recurrent rectal cancer, Hu et al. compared CRT [FOLFOX4+threedimensional conformal radiotherapy (3-DCRT) and RT]. Patients in the CRT group had a significantly higher 2-year survival rate, with a substantially higher response rate $(56 \%$ vs. 40\%) (23). You et al. also assessed the outcome of concurrent CRT using oxaliplatin (oxaliplatin+pelvic 
irradiation) in 96 patients with locally recurrent rectal cancer, and reported a CR rate of $14 \%$ and a PR rate of $61 \%$ (24). Cai et al. reported a CR rate of $5.6 \%$ following CRT with capecitabine and irinotecan with intensity modulated radiation therapy (IMRT) (45 Gy) associated with a 3-year survival rate of $36.5 \%$; the 3 -year local progression-free survival rate was $33.9 \%$ after a median follow-up of 31 months. As for adverse events, grade 4 leukopenia was $4.8 \%$, grade 3 diarrhea was $22.5 \%$, and toxicity was within a permissible range (25). Although CRT using doublet chemotherapy regimens for locally recurrent rectal cancer improved local control as well as survival rates in the above-mentioned reports, there was no significant difference in overall survival between CRT in the doublet regimen group and that of the 5-FU-based regimen group in our study. Possible explanations for this result are differences in patients' backgrounds and the limited number of patients in our study.

This study has several limitations. First, we only evaluated a small number of patients. Second, many of the patients were censored cases, which may have led to overestimation of the OS results. Third, the observation period of patients treated with the modified FOLFOX6+RT regimen was relatively short. Despite these limitations, our study suggests that CRT for patients with local recurrence of rectal cancer is an efficacious treatment modality that provides local control and improves survival rates.

In conclusion, CRT for local recurrence of rectal cancer without distant metastasis may have a meaningful survival benefit and a relatively manageable toxicity profile in clinical practice. Further research on a large population is needed in order to elucidate the treatment outcome of CRT for local recurrent rectal cancer.

\section{Conflicts of Interest}

The Authors declare no conflicts of interest regarding this study.

\section{Authors' Contributions}

All other Authors have contributed to data collection and interpretation, and critically reviewed the manuscript. All Authors approved the final version of the manuscript, and agree to be accountable for all aspects of the work in ensuring that questions related to the accuracy or integrity of any part of the work are appropriately investigated and resolved.

\section{References}

1 Ikoma N, You YN, Bednarski BK, Rodriguez-Bigas MA, Eng C, Das P, Kopetz S, Messick C, Skibber JM and Chang GJ: Impact of recurrence and salvage surgery on survival after multidisciplinary treatment of rectal cancer. J Clin Oncol 35(23): 2631-2638, 2017. PMID: 28657814. DOI: 10.1200/JCO.2016. 72.1464
2 Bosset JF, Collette L, Calais G, Mineur L, Maingon P, Radosevic-Jelic L, Daban A, Bardet E, Beny A and Ollier JC: Chemotherapy with preoperative radiotherapy in rectal cancer. N Engl J Med 355(11): 1114-1123, 2006. PMID: 16971718. DOI: 10.1056/NEJMoa060829

3 Gerard JP, Conroy T, Bonnetain F, Bouche O, Chapet O, ClosonDejardin MT, Untereiner M, Leduc B, Francois E, Maurel J, Seitz JF, Buecher B, Mackiewicz R, Ducreux M and Bedenne L: Preoperative radiotherapy with or without concurrent fluorouracil and leucovorin in t3-4 rectal cancers: Results of FFCD 9203. J Clin Oncol 24(28): 4620-4625, 2006. PMID: 17008704. DOI: $10.1200 / J C O .2006 .06 .7629$

4 Park IJ, You YN, Agarwal A, Skibber JM, Rodriguez-Bigas MA, Eng C, Feig BW, Das P, Krishnan S, Crane CH, Hu CY and Chang GJ: Neoadjuvant treatment response as an early response indicator for patients with rectal cancer. J Clin Oncol 30(15): 1770-1776, 2012. PMID: 22493423. DOI: 10.1200/JCO.2011. 39.7901

5 Rahbari NN, Elbers H, Askoxylakis V, Motschall E, Bork U, Buchler MW, Weitz $\mathrm{J}$ and Koch M: Neoadjuvant radiotherapy for rectal cancer: Meta-analysis of randomized controlled trials. Ann Surg Oncol 20(13): 4169-4182, 2013. PMID: 24002536. DOI: $10.1245 / \mathrm{s} 10434-013-3198-9$

6 Wanebo HJ, Koness RJ, Vezeridis MP, Cohen SI and Wrobleski DE: Pelvic resection of recurrent rectal cancer. Ann Surg 220(4): 586-595; discussion 595-587, 1994. PMID: 7524455.

7 Ogunbiyi OA, McKenna K, Birnbaum EH, Fleshman JW and Kodner IJ: Aggressive surgical management of recurrent rectal cancer- is it worthwhile? Dis Colon Rectum 40(2): 150-155, 1997. PMID: 9075748.

8 Hofheinz RD, Wenz F, Post S, Matzdorff A, Laechelt S, Hartmann JT, Muller L, Link H, Moehler M, Kettner E, Fritz E, Hieber U, Lindemann HW, Grunewald M, Kremers S, Constantin C, Hipp M, Hartung G, Gencer D, Kienle P, Burkholder I and Hochhaus A: Chemoradiotherapy with capecitabine versus fluorouracil for locally advanced rectal cancer: A randomised, multicentre, noninferiority, phase 3 trial. Lancet Oncol 13(6): 579-588, 2012. PMID: 22503032. DOI: 10.1016/S1470-2045(12)70116-X

9 Braendengen $\mathrm{M}$, Tveit KM, Berglund A, Birkemeyer E, Frykholm G, Pahlman L, Wiig JN, Bystrom P, Bujko K and Glimelius B: Randomized phase iii study comparing preoperative radiotherapy with chemoradiotherapy in nonresectable rectal cancer. J Clin Oncol 26(22): 3687-3694, 2008. PMID: 18669453. DOI: 10.1200/JCO.2007.15.3858

10 Bhangu A, Ali SM, Cunningham D, Brown G and Tekkis P: Comparison of long-term survival outcome of operative vs nonoperative management of recurrent rectal cancer. Colorectal Dis 15(2): 156-163, 2013. DOI: 10.1111/j.1463-1318.2012.031 23.x

11 Rahbari NN, Ulrich AB, Bruckner T, Munter M, Nickles A, Contin P, Loffler T, Reissfelder C, Koch M, Buchler MW and Weitz J: Surgery for locally recurrent rectal cancer in the era of total mesorectal excision: Is there still a chance for cure? Ann Surg 253(3): 522-533, 2011. PMID: 21209587. DOI: 10.1097/ SLA.0b013e3182096d4f

12 Pacelli F, Tortorelli AP, Rosa F, Bossola M, Sanchez AM, Papa V, Valentini V and Doglietto GB: Locally recurrent rectal cancer: Prognostic factors and long-term outcomes of multimodal therapy. Ann Surg Oncol 17(1): 152-162, 2010. PMID: 198347 66. DOI: $10.1245 / \mathrm{s} 10434-009-0737-5$ 
13 Tanis PJ, Doeksen A and van Lanschot JJ: Intentionally curative treatment of locally recurrent rectal cancer: A systematic review. Can J Surg 56(2): 135-144, 2013. PMID: 23517634. DOI: $10.1503 /$ cjs.025911

14 Moertel CG, Childs DS Jr., Reitemeier RJ, Colby MY, Jr. and Holbrook MA: Combined 5-fluorouracil and supervoltage radiation therapy of locally unresectable gastrointestinal cancer. Lancet 2(7626): 865-867, 1969. PMID: 4186452.

15 Xiong HQ, Gunderson LL, Yao J and Ajani JA: Chemoradiation for resectable gastric cancer. Lancet Oncol 4(8): 498-505, 2003. PMID: 12901965.

16 Nielsen MB, Laurberg S and Holm T: Current management of locally recurrent rectal cancer. Colorectal Dis 13(7): 732-742, 2011. PMID: 20041928. DOI: 10.1111/j.1463-1318.2009.021 67.x

17 Glynne-Jones R, Falk S, Maughan TS, Meadows HM and Sebag-Montefiore D: A phase i/ii study of irinotecan when added to 5-fluorouracil and leucovorin and pelvic radiation in locally advanced rectal cancer: A colorectal clinical oncology group study. Br J Cancer 96(4): 551-558, 2007. PMID: 17262086. DOI: $10.1038 /$ sj.bjc. 6603570

18 Ito Y, Ohtsu A, Ishikura S, Boku N, Nihei K, Ogino T and Ikeda $\mathrm{H}$ : Efficacy of chemoradiotherapy on pain relief in patients with intrapelvic recurrence of rectal cancer. Jpn J Clin Oncol 33(4): 180-185, 2003. PMID: 12810832. DOI: 10.1093/jjco/hyg036

19 de Gramont A, Figer A, Seymour M, Homerin M, Hmissi A, Cassidy J, Boni C, Cortes-Funes H, Cervantes A, Freyer G, Papamichael D, Le Bail N, Louvet C, Hendler D, de Braud F, Wilson C, Morvan F and Bonetti A: Leucovorin and fluorouracil with or without oxaliplatin as first-line treatment in advanced colorectal cancer. J Clin Oncol 18(16): 2938-2947, 2000. PMID: 10944126. DOI: $10.1200 / J C O .2000 .18 .16 .2938$

20 Goldberg RM, Sargent DJ, Morton RF, Fuchs CS, Ramanathan RK, Williamson SK, Findlay BP, Pitot HC and Alberts SR: A randomized controlled trial of fluorouracil plus leucovorin, irinotecan, and oxaliplatin combinations in patients with previously untreated metastatic colorectal cancer. J Clin Oncol 22(1): 23-30, 2004. PMID: 14665611. DOI: 10.1200/JCO.2004. 09.046
21 Garcia-Aguilar J, Renfro LA, Chow OS, Shi Q, Carrero XW, Lynn PB, Thomas CR, Jr., Chan E, Cataldo PA, Marcet JE, Medich DS, Johnson CS, Oommen SC, Wolff BG, Pigazzi A, McNevin SM, Pons RK and Bleday R: Organ preservation for clinical t2n0 distal rectal cancer using neoadjuvant chemoradiotherapy and local excision (acosog z6041): Results of an open-label, single-arm, multi-institutional, phase 2 trial. Lancet Oncol 16(15): 1537-1546, 2015. PMID: 26474521. DOI: 10.1016/S1470-2045(15)00215-6

22 Kennelly RP, Heeney A, White A, Fennelly D, Sheahan K, Hyland JM, O'Connell PR and Winter DC: A prospective analysis of patient outcome following treatment of $\mathrm{t} 3$ rectal cancer with neo-adjuvant chemoradiotherapy and transanal excision. Int J Colorectal Dis 27(6): 759-764, 2012. PMID: 22173716. DOI: $10.1007 / \mathrm{s} 00384-011-1388-0$

$23 \mathrm{Hu}$ JB, Sun XN, Yang QC, Xu J, Wang Q and He C: Threedimensional conformal radiotherapy combined with folfox 4 chemotherapy for unresectable recurrent rectal cancer. World J Gastroenterol 12(16): 2610-2614, 2006. PMID: 16688811. DOI: 10.3748/wjg.v12.i16.2610

24 You YT, Chen JS, Wang JY, Tang R, Changchien CR, Chiang JM, Yeh CY, Hsieh PS, Tasi WS, Hung HY, You JF and Chiang SF: Concurrent chemoradiotherapy in the treatment of locally recurrent rectal cancer. Hepatogastroenterology 60(121): 94-98, 2013. PMID: 22784941. DOI: 10.5754/hge12503

25 Cai G, Zhu J, Palmer JD, Xu Y, Hu W, Gu W, Cai S and Zhang Z: CAPIRI-IMRT: A phase II study of concurrent capecitabine and irinotecan with intensity-modulated radiation therapy for the treatment of recurrent rectal cancer. Radiat Oncol 10(57), 2015. PMID: 25889149. DOI: 10.1186/s13014-015-0360-5

Received May 2, 2019

Revised June 8, 2019

Accepted June 12, 2019 